\title{
Influenza vaccination rates and informed consent in Dutch nursing homes: survey of nursing home physicians
}

\author{
Marcel Verweij, Mariëtte van den Hoven
}

Centre for Bioethics and Health Law, Utrecht University, Heidelberglaan 2, NL-3584 CS,

Utrecht,

Netherlands Marcel Verweij research fellow

Mariëtte van den Hoven junior researcher

Correspondence to: M Verweij mverweij@theo. uunl

BMJ 2002;324:328
Influenza is a major cause of morbidity and mortality among residents of nursing homes. ${ }^{1}$ Many nursing homes therefore aim at high vaccination rates. To meet this aim some homes use tacit consent policies, in which the vaccine is given unless residents or their proxies state that they do not want it. Such policies deviate from standard (express) consent procedures, which require that vaccination occurs only if the resident or his or her proxy gives consent. Is this deviation from standard informed consent procedures justified? We explored consent procedures and vaccination rates in Dutch nursing homes to determine the effects of current practice.

\section{Participants, methods, and results}

In October 2000, we sent a questionnaire to all (353) nursing homes in the Netherlands for completion by one of the nursing home physicians. Doctors were asked to provide exact vaccination rates or, if that was not possible, to estimate the rate within $10 \%$ ranges (90-100\%, 80-90\%, etc). The questionnaire also asked about vaccination and consent policies. We analysed data using SPSS-9. Differences were considered significant if $\mathrm{P}<0.05$.

We received 245 completed questionnaires. Eighteen nursing homes seemed to have shut down or merged into other institutions. We therefore counted the response rate as $73 \%(245 / 335)$. The average vaccination rate (based on exact information) in nursing homes was $86 \%$. When we combined exact and estimated data, 120 homes $(49 \%)$ had a vaccination rate of $90 \%$ or higher (table).

Ninety eight homes had a written vaccination policy. These institutions had lower vaccination rates than homes without written policies. Only 53 (22\%) nursing homes asked healthcare workers to be vaccinated.

In all, 106 institutions followed tacit consent procedures for all residents. Nursing homes with tacit consent procedures had higher vaccination rates than

Vaccination rates of Dutch nursing homes according to policies on vaccination and consent $^{\star}$

\begin{tabular}{|c|c|c|c|c|}
\hline & $\begin{array}{c}\text { No (\%) } \\
\text { of homes }\end{array}$ & $\begin{array}{c}\text { Mean } \\
\text { vaccination } \\
\text { rate (No of } \\
\text { homes) } \dagger\end{array}$ & $\begin{array}{c}\text { No }(\%) \\
\text { with } \geqslant \mathbf{8 0} \% \\
\text { vaccinationf }\end{array}$ & $\begin{array}{c}\text { No }(\%) \\
\text { with } \geqslant 90 \% \\
\text { vaccinationł }\end{array}$ \\
\hline All responding nursing homes & $245(100)$ & $86 \%(180)$ & 199/243 (82) & $120 / 243(49)$ \\
\hline Institutions with written policyl & $98(40)$ & $84 \%(73)$ & $74 / 98(76)$ & $48 / 98(49) \S$ \\
\hline Institutions without written policy & $135(55)$ & $88 \%(100)$ & 118/133 (89) & $68 / 133(51) \S$ \\
\hline Always required express consent ${ }^{\star *}$ & $100(41)$ & $82 \%(73)$ & $74 / 98(76)$ & $41 / 98(42)$ \\
\hline Tacit consent always sufficient ${ }^{\star *}$ & $106(43)$ & $89 \%(81)$ & 96/106 (91) & $64 / 106(60)$ \\
\hline
\end{tabular}

*Differences between institutions with and without written policy and between those requiring express and tacit consent are significant $(\mathrm{P}<0.03)$.

tBased on exact vaccination rates per nursing home.

fBased on exact and estimated vaccination rates.

\&Not significant.

INine respondents did not know whether the home had a written policy and three gave no information

**35 homes had different policies on consent for competent and incompetent residents and one gave no

information. institutions that required express consent from all residents (mean rate $89 \%$ \% $82 \%, \mathrm{P}<0.001$ )

\section{Comment}

We have shown that homes that use tacit consent have higher vaccination rates than those which require express consent, but the difference may not be sufficient to justify use of such a policy. Tacit consent implies that residents and their proxies are informed about vaccination and are vaccinated unless they refuse. This procedure deviates from standard informed consent procedures $^{2}$ and therefore raises ethical problems. If tacit consent is presumed, the health professional will often not be certain whether the person received the relevant information or whether the information was adequately understood. Moreover, it is unclear that a voluntary choice was made.

There is a potentially strong collective argument for aiming at high vaccination rates and hence for preferring tacit consent. ${ }^{3}$ High immunisation rates may result in herd immunity, which increases protection for all residents, including the weakest patients. Moreover, it may reduce the risk of an influenza outbreak that will disrupt daily institutional life and care. However, there are some problems with this argument. Firstly, our survey shows that many nursing homes that use express consent procedures have vaccination rates $(>80 \%)$ that may be sufficient for herd immunity. Hence, tacit consent is not necessary for herd immunity. Secondly, tacit consent can be valid only if everyone is aware that they have a choice. This puts far reaching demands on the information process. Lastly, only 53 of the 245 institutions asked employees to be vaccinated. We suspect that vaccination rates among nurses are low, and this will frustrate herd immunity within the institution. $^{45}$ If vaccination of healthcare workers is inadequate, the aim of herd immunity is not a sufficient argument to deviate from standard consent procedures.

Contributors: MV and MvdH contributed to the conception and design of the study and to analysis and interpretation of the data. $\mathrm{MvdH}$ is the guarantor.

Funding: Health Research and Development Council of the Netherlands.

Competing interests: None declared.

1 Gross PA, Hemogenes AW, Sacks HS, Lan J, Levandavski RA. The efficacy of influenza vaccine in elderly persons. A meta-analysis and review of the literature. Ann Intern Med 1995;123:518-27.

2 Beauchamp TL, Childress JF. Principles of biomedical ethics. 4th ed. New York: Oxford University Press, 1994.

3. Verweij M. Individual and collective considerations in public health: influenza vaccination in nursing homes. Bioethics 2001;15:536-46.

4 Drinka PJ, Gravenstein S, Krause P, Schilling M, Miller BA, Shult P. Outbreaks of influenza A and B in a highly immunized nursing home population.J Fam Pract 1997;45:509-14.

5 Nicholson KG. Should staff in long-stay hospitals for elderly patients be vaccinated against influenza? Lancet 2000;355:83-4.

(Accepted 13 September 2001) 